\title{
Regulação/avaliação da Educação Superior a Distância: multiplicidade de atores institucionais, labirinto de atos oficiais e avaliação regulatória
}

\author{
Regulation/evaluation of Distance Higher Education: multiplicity of institutional \\ actors, labyrinth of official acts, and regulatory evaluation \\ Regulación/evaluación de la Educación Superior a Distancia: multiplicidad de \\ actores institucionales, laberinto de actos oficiales y evaluación regulatoria
}

STELLA CECILIA DUARTE SEGENREICH

\begin{abstract}
Resumo: Com base na definição de Cabrito sobre regulação, este relato de estudo objetiva relacionar a atuação de quatro atores institucionais do MEC, desde sua origem, com as políticas públicas relacionadas à regulação/avaliação da educação a distância, com destaque para sua atuação nos atos oficiais do último biênio. Trata-se de uma pesquisa exploratória, fruto da consulta a documentos legais e institucionais assim como artigos de periódicos. Os resultados demonstraram a pluralidade de atores institucionais atuando junto à $\mathrm{EaD}$, a construção de um labirinto de atos oficiais e instrumentos de avaliação regulatória que mudam de acordo com as orientações governamentais vigentes, sugerindo a continuidade da pesquisa na realidade das universidades públicas e privadas.
\end{abstract}

Palavras-chave: Educação Superior, Educação a Distância, Regulação/avaliação, Atores institucionais.

\begin{abstract}
Based on Cabrito's definition of regulation, this study aims to relate the performance of four institutional actors of MEC, since its origins with the public policies related to the regulation/evaluation of distance education, especially its performance in official acts of the last biennium. This is an exploratory research that shows the results of the consultation of legal and institutional documents, as well as articles from periodicals. The results demonstrate the plurality of institutional actors related to distance education - $\mathrm{EaD}$, and the construction of a labyrinth of official acts and instruments of regulatory evaluation that change according to the current governmental guidelines, suggesting the continuity of research in the reality of public and private universities.
\end{abstract}

Keywords: higher education, distance education, regulation/evaluation, institutional actors

Resumen: Con base en la definición de Cabrito sobre regulación, este informe de estudio objetiva relacionar la actuación de cuatro actores institucionales del MEC, desde su origen, con las políticas públicas relacionadas a la regulación / evaluación de la educación a distancia, con destaque para su actuación en los actos oficiales del último bienio. Se trata de una investigación exploratoria, fruto de la consulta a documentos legales e institucionales así como artículos de periódicos. Los resultados demostraron la pluralidad de actores institucionales actuando 
en la $\mathrm{EaD}$, la construcción de un laberinto de actos oficiales e instrumentos de evaluación regulatoria que cambian de acuerdo con las orientaciones gubernamentales vigentes, sugiriendo la continuidad de la investigación en la realidad de las universidades públicas y privadas.

Palabras clave: Educación superior, educación a distancia, regulación/ evaluación, actores institucionales.

\section{INTRODUÇÃO}

Este texto objetiva apresentar alguns resultados do mapeamento de diferentes atores institucionais que se relacionam com os procedimentos de regulação e avaliação da educação superior na modalidade a distância, no Brasil. Foi dado destaque à atuação de cinco atores institucionais da administração direta e indireta do Ministério da Educação e Cultura (MEC), desde sua criação. Complementando os atores institucionais do MEC, destacamos, também, dois órgãos colegiados desse ministério.

Quanto aos procedimentos de regulação, foi reservado um espaço para comentar os atos oficiais do biênio 2016/2017, tendo em vista que esses atos incluem significativas mudanças na educação a distância $(\mathrm{EaD})$. Em relação à avaliação propriamente dita, a proposta do Sistema Nacional de Avaliação da Educação Superior (SINAES) foi a referência conceitual utilizada como suporte para uma análise preliminar da regulação/avaliação da $\mathrm{EaD}$ e encaminhamento para novos estudos.

Basicamente, trata-se de uma pesquisa documental e bibliográfica, fruto da consulta a documentos legais (leis, decretos, portarias, resoluções, principalmente) e institucionais (manifestações de diferentes organizações com interesse na modalidade $\mathrm{EaD}$ ), assim como artigos publicados em periódicos. O método da pesquisa documental é central nesta temática. Segundo Quivy e Campehout (2005), "do ponto de vista da fonte pode tratar-se de documentos manuscritos, impressos ou audiovisuais, oficiais ou privados, pessoais ou provenientes de um organismo, contendo colunas de números ou textos" (p. 202).

Alguns recortes nos arquivos levantados se fizeram necessários para estabelecer um dimensionamento adequado do texto. O relacionamento público/ privado não será explorado, tendo em vista que a crescente expansão dos cursos de graduação na modalidade $\mathrm{EaD}$ e, particularmente da rede privada com fins lucrativos, tem sido analisada em outros estudos, com a utilização de dados estatísticos. Segenreich e Castanheira (2015), por exemplo, constataram que a matrícula em cursos a distância passou de $0,06 \%$ do total de matrículas em 2000 para 15,8\% em 2013, de acordo com os censos dos referidos anos. Pelos dados 
do Censo da Educação Superior de 2016 (INEP, 2017) este percentual chegou a $49,6 \%$, representando um total de 1.494 .418 matrículas, das quais $91,8 \%$ estão na rede privada. Outra dimensão de estudo implícita no texto será o processo de diferenciação de arquiteturas acadêmicas que emergiram no bojo da trajetória da educação a distância no Brasil, tais como: a Universidade Aberta do Brasil (UAB), na rede pública, e os Grupos Educacionais de instituições privadas que se agigantaram nos últimos anos, lançaram ações na Bolsa de Valores no final da década de 2000 e têm exercido pressão mercadológica nos debates sobre a EaD (SEGENREICH; CASTANHEIRA, 2015).

Será descrita, inicialmente, a trajetória de alguns dos principais atores institucionais da estrutura do MEC envolvidos nas questões relativas à regulação e à avaliação regulatória da educação a distância, assim como a identificação da presença de outras entidades envolvidas. A percepção da importância de mapear estes atores institucionais surgiu da definição de regulação de Belmiro Cabrito em sua análise do ensino superior em Portugal, tal como foi adotada pelo grupo de pesquisadores da Rede Universitas/BR no seu novo projeto de pesquisa. Assim se manifesta Cabrito:

Em termos amplos, e no quadro institucional, entendo por regulação o modo como os portadores de autoridade coordenam, controlam e influenciam o sistema educativo e seus atores, por meio de regras, normas, pressões e constrangimentos, condicionando a ação daqueles atores em função dos objetivos políticos que perseguem. (apud MANCEBO; OLIVEIRA; SILVA JÚNIOR, 2017, p.10)

Em sequência, serão registrados os atos oficiais aprovados no biênio 2016/ 2017, nos quais estes atores estão atuando no momento. Finalizando o corpo do texto, foi incluída uma primeira abordagem do estudo que está se iniciando sobre a controvertida relação entre regulação e avaliação na EaD. Nas considerações finais estão sintetizados os resultados obtidos e retomadas algumas propostas de investigação.

\section{ATORES INSTITUCIONAIS DA ADMINISTRAÇÃO DO MEC}

Do organograma atual do MEC foram destacados cinco órgãos da estrutura de sua administração direta e indireta, sendo o último deles já extinto em 2011: o Instituto Nacional de Estudos e Pesquisas Educacionais Anísio Teixeira (INEP); a Coordenação de Aperfeiçoamento de Pessoal de Nível Superior (CAPES); a Secretaria de Educação Superior (SESu); a Secretaria de Educação a Distância (SEED) e a Secretaria de Regulação e Supervisão da Educação Superior (SERES). 
O INEP (2018) foi criado com o nome de Instituto Nacional de Pedagogia em 1937, passando a funcionar no ano seguinte com a denominação de Instituto Nacional de Estudos Pedagógicos. Sua função inicial era se tornar uma fonte de documentação e de desenvolvimento de atividades de intercâmbio e assistência técnica. Ao tomar posse em 1952, como diretor do INEP, Anísio Teixeira enfatizou sua função de desenvolvimento de pesquisa organizando, inclusive, centros de pesquisa regionais no Brasil.

Na década de 1970, após várias alterações de estrutura e de funções o modelo idealizado por Anísio Teixeira, com base nos centros de pesquisa, é desmontado e a sede do INEP é transferida em 1976 para Brasília. A partir de 1985, ela retoma sua função básica de suporte e assessoramento aos centros decisórios do Ministério da Educação. Em 1997, nova reestruturação do órgão transforma o INEP em autarquia vinculada ao MEC e lhe atribui a responsabilidade pelos levantamentos estatísticos, já com o objetivo de orientar a formulação de políticas do MEC. No que se refere à sua relação com a EaD é importante destacar que os censos de educação superior passam a registrar os dados sobre a educação a distância a partir do ano 2000.

Em abril de 2002 é atribuída ao INEP, mediante portaria do MEC, a responsabilidade pela definição das diretrizes para a organização e execução da avaliação das instituições de educação superior e das condições de ensino dos cursos de graduação. Dois anos após a promulgação da lei que criou o SINAES em 2004, o Decreto no 5.773/2006 estabelece, em seu artigo 59, que o SINAES será operacionalizado pelo INEP, e que sua avaliação servirá como referencial básico para a regulação de instituições e cursos sem resultar em atribuição de conceitos (BRASIL, 2006).

Dois decretos, aprovados no final de 2007, servem para fortalecer a dimensão regulatória da avaliação por parte do INEP. No Decreto no 6.303 de 12 de dezembro de 2007, esta avaliação passa a resultar na atribuição de conceitos, conforme uma escala de cinco níveis (BRASIL, 2007). Oito dias depois, em outro decreto, o INEP é mais uma vez reestruturado mediante a criação do Departamento de Avaliação da Educação Superior (DAES) para assumir a implementação do SINAES.

No período 2010/2011, o recém criado DAES faz uma revisão dos instrumentos até então utilizados no SINAES. Os novos modelos, mantendo a mesma estrutura fechada, são apresentados em maio de 2011. Na última versão desses instrumentos, publicada em outubro de 2017, os instrumentos de avaliação do INEP continuam incorporados ao processo de regulação como condição prévia de credenciamento de IES e autorização/credenciamento de cursos, tendo a especificidade da educação a distância retratada em alguns itens. 
A CAPES tem sua origem em uma Campanha Nacional de Aperfeiçoamento de Pessoal de Nível Superior criada em julho de 1951, com o objetivo de "assegurar a existência de pessoal especializado em quantidade e qualidade suficientes para atender às necessidades dos empreendimentos públicos e privados que visam ao desenvolvimento do país” (MEC/CAPES, 2018).

A avaliação formal dos cursos de pós-graduação stricto sensu foi introduzida em 1976, a partir pelo primeiro Plano Nacional de Pós-Graduação (PNPg), que atribuiu à CAPES a coordenação da política nacional de pós-graduação. A avaliação foi concebida inicialmente como um processo contínuo e um modelo flexível que foi se tornando rígido com o passar dos anos. A continuidade administrativa torna-se uma marca da instituição, que se destaca na formulação, acompanhamento e execução da Política Nacional de Pós-Graduação.

Em 1992, a CAPES é instituída como Fundação Pública e, em 1995, passa por uma reestruturação da qual sai fortalecida como responsável pelo acompanhamento e avaliação dos cursos de pós-graduação stricto sensu, sendo esta atribuição confirmada quando da criação do SINAES em 2004.

No que se refere à relação com a educação a distância, é importante registrar que no Decreto no 5622/2005 (BRASIL, 2005) que regula art. 80 da LDB/96, a atribuição exclusiva da CAPES de regulamentar a pós-graduação stricto sensu também é mantida para oferta de cursos de mestrado e doutorado a distância.

A partir de 2007, a chamada "Nova CAPES" passa a ser responsável pela indução e fomento da formação inicial e continuada de professores para a educação básica utilizando recursos e tecnologias da educação a distância, especialmente na formação continuada e esta atribuição é consolidada em 2009, pela Política Nacional de Formação de Profissionais do Magistério da Educação Básica. Neste mesmo ano a CAPES passa a ser responsável pela condução operacional da Universidade Aberta do Brasil (UAB), criada pela Portaria no318/2009 (BRASIL/MEC, 2009a), que antes era atribuição da SEED/MEC. A Capes assume efetivamente sua nova atribuição por meio da criação da Diretoria Educação a Distância (DED). Esta diretoria tem realizado vários estudos sobre o funcionamento da UAB, marcando a presença das questões relacionadas à educação a distância nesta fundação. Atualmente a DED funciona com três coordenações gerais: Coordenação Geral de Inovação em Ensino a Distância (CGIE); Coordenação Geral de Programas e Cursos em Ensino a Distância (CGPC) e Coordenação Geral de Supervisão e Fomento (CGFO).

A SESu foi criada em 1979, originária do antigo Departamento de Assuntos Universitários (DAU). De 1993 a 2011 ela atuou em parceria com a 
Secretaria de Educação de Educação a Distância (SEED) nos assuntos ligados à $\mathrm{EaD}$, com a crescente presença decisória dessa secretaria nos atos oficiais até ela ser extinta em 2011.

Atualmente, a SESu é apresentada como uma unidade do MEC responsável por planejar, orientar, coordenar e supervisionar o processo de formulação e implementação da Política Nacional de Educação Superior. Conforme a LDB/96, a manutenção, a supervisão e o desenvolvimento das Ifes também são de responsabilidade da SESu, de forma que o órgão constitui a principal interface do Ministério com as sessenta e três universidades federais espalhadas pelo território nacional (MEC/SESu, 2018).

Suas atividades são desenvolvidas por três Diretorias e oito Coordenações Gerais. Destaca-se, entre elas, a Diretoria de Políticas e Programas de Graduação (DIPES) pelo fato dela se ocupar pela gestão, no âmbito do MEC, do Programa Universidade para Todos (Prouni) e do Fundo de Financiamento Estudantil (Fies); ambos objeto de grande interesse das IES privadas que oferecem cursos a distância.

A SEED foi criada em maio de 1996, meses antes da inserção da EaD como modalidade de educação superior, pelo artigo 80 da LDB/96. No início, suas competências estavam mais vinculadas às tecnologias educacionais e pedagógicas a serem utilizadas nesta modalidade educacional

Em 19 de dezembro de 2005, o artigo 80 da LDB/96 é finalmente regulamentado pelo Decreto $n^{\circ} 5.622$ (BRASIL, 2005). No seu texto a SEED não é mencionada explicitamente, ficando toda a indicação de atribuições para o Ministério da Educação como um todo. Já no Decreto no 5.773 de 9 de maio de 2006 (BRASIL, 2006), as secretarias do MEC são reconhecidas nas suas atribuições específicas. Ao dispor sobre o exercício das funções de regulação, supervisão e avaliação para o ensino superior, tanto presencial como a distância, é dedicada toda uma subseção ao credenciamento específico para oferta da $\mathrm{EaD}$ transferindo a instrução desse processo à SESu e à SETEC, com a colaboração da SEED conforme o caso. Entre as atribuições da SEED ainda permanece o compartilhamento de decisão, no que se refere, principalmente, às tecnologias e processos próprios da educação a distância.

No início do ano seguinte, pelo artigo $7^{\circ}$ da Portaria Normativa $n^{\circ} 1$, de 10 de janeiro de 2007 (BRASIL/MEC, 2007a) fica estipulado:

\footnotetext{
A avaliação de instituições e cursos na modalidade a distância será feita com base em instrumentos específicos de avaliação de instituições e cursos a distância, editados, mediante iniciativa da Secretaria de Educação a Distância (SEED), na forma prevista no art. $5^{\circ}, \int 4^{\circ}$, III e IV, do Decreto no 5.773 , de 2006 , até o dia 15 de maio de 2007.
} 
Na Portaria n 2/2007 (BRASIL/MEC, 2007b), baixada no mesmo dia e voltada especificamente para a educação a distância, a SEED já aparece como órgão de supervisão.

Finalmente, pelo Decreto 6.303 de 12 de dezembro de 2007 (BRASIL, 2007) aumenta o poder de intervenção da SEED alterando dispositivos dos decretos de 2005 e 2006 acima mencionados. Ao definir as competências da Secretaria de Educação a Distância no $\int 4^{\circ}$ do artigo $5^{\circ}$ substitui as expressões "exarar parecer" por instruir, decidir, promover diligências; enfim, "exercer a supervisão dos cursos de graduação e seqüenciais a distância, no que se refere à sua área de atuação".

Vale registrar que, no decorrer de 2007, a SEED havia elaborado e apresentado em agosto sua proposta de Referenciais de Qualidade da Educação a Distância, seguindo o disposto no Decreto 5.773/2006. Estima-se que as mudanças de atribuição introduzidas pelo Decreto 6.303/2007, permitiram que, entre 2008 e 2010 a SEED e o INEP elaborassem, em conjunto, instrumentos específicos de avaliação para a educação a distância tomando como base os referenciais de qualidade propostos pela SEED. Entretanto, como a SEED foi extinta pelo Decreto $n^{\circ} 7.480 / 2011$ (BRASIL, 2011), estes instrumentos foram eliminados neste mesmo ano pela recém-criada Secretaria de Regulação da Educação Superior (SERES), que será apresentada em seguida.

A SERES foi criada em 17/4/2011 pelo mesmo ato oficial que extinguiu a SEED, absorvendo competências antes desempenhadas por três secretarias do MEC: SESu, SETEC e a extinta SEED. Neste decreto foi prevista a criação uma Diretoria de Regulação e Supervisão da Educação a Distância juntamente com uma secretaria voltada para a educação superior e uma terceira para a educação profissional e tecnológica. Elas são substituídas, no Decreto $n^{\circ}$ 7.690/2012 (BRASIL, 2012), por três outras diretorias, estruturadas em função de suas atribuições: política regulatória, supervisão da educação superior e regulação da educação superior. A EaD passa a se fazer presente, como coordenação, nas duas diretorias encarregadas da supervisão e da regulação da educação superior. Em 2013, nova reformulação extingue diretorias e coordenações. Consultando o portal da SERES (MEC/SERES, 2018) verifica-se que somente permanece uma reduzida Coordenação de Regulação da Ead (Coread) na Diretoria de Regulação da Educação Superior (DIREG).

Atualmente a SERES é responsável, junto com o INEP, pela regulação e avaliação do sistema federal de educação superior. O órgão tem uma trajetória curta mas veio exercendo gradativo aumento de poder no período 2011 - 2017. Quanto à vinculação com a $\mathrm{EaD}$, permaneceu somente a coordenação acima citada (Coread). 
Sintetizando a trajetória desses quatro órgãos, em termos de sua participação formal na trajetória da $\mathrm{EaD}$, foi construído o Quadro 1 no qual estão comparadas cronologicamente as interfaces dos atores institucionais do MEC com a EaD.

\section{Quadro 1 - Interfaces dos atores institucionais do MEC com a EaD}

\begin{tabular}{|c|c|c|c|c|c|}
\hline Anos & INEP (1937) & CAPES (1951) & SESu (1979) & SEED (1996) & SERES (2011) \\
\hline 2000 & \multirow{2}{*}{ Estatísticas } & & $\begin{array}{c}\text { Credenc. IES/ } \\
\text { Autoriz. Cursos } \\
\text { EaD }\end{array}$ & $\begin{array}{c}\text { Credenc. IES/ } \\
\text { Autoriz. Cursos } \\
\text { EaD }\end{array}$ & \\
\hline 2007 & & $\begin{array}{l}\text { UAB/Diretoria } \\
\text { de EaD }\end{array}$ & & $\begin{array}{c}\text { Referenciais de } \\
\text { qualidade } \mathrm{EaD}\end{array}$ & \\
\hline 2008 & \multirow{3}{*}{$\begin{array}{l}\text { SEED/INEP } \\
\text { Instrumentos de } \\
\text { avaliação da } \\
\text { EaD }\end{array}$} & & & & \\
\hline 2009 & & $\begin{array}{c}\text { Coordenação } \\
\text { operacional da } \\
\text { UAB }\end{array}$ & & \multirow{2}{*}{$\begin{array}{c}\text { SEED/INEP } \\
\text { Instrumentos } \\
\text { de avaliação da } \\
\text { EaD }\end{array}$} & \\
\hline 2010 & & & & & \\
\hline 2011 & \multirow{4}{*}{$\begin{array}{l}\text { Avaliação } \\
\text { dentro do } \\
\text { processo } \\
\text { regulatório das } \\
\text { IES e cursos } \\
\text { presenciais e } \\
\text { EaD }\end{array}$} & & \multirow{4}{*}{$\begin{array}{l}\text { Recursos de } \\
\text { decisões da } \\
\text { SERES - EaD }\end{array}$} & $\begin{array}{l}\text { Extinção da } \\
\text { SEEED }\end{array}$ & $\begin{array}{c}\text { Criação da } \\
\text { SERES }\end{array}$ \\
\hline \multirow{3}{*}{2012} & & & & & $\begin{array}{c}\text { Diretoria de } \\
\text { Regul. e Superv. } \\
\text { EaD }\end{array}$ \\
\hline & & & & & $\begin{array}{l}\text { Extinta Diretoria } \\
\text { Criada Coread }\end{array}$ \\
\hline & & & & & $\begin{array}{c}\text { Credenc. IES/ } \\
\text { Autoriz. Cursos } \\
\text { EaD }\end{array}$ \\
\hline
\end{tabular}

Fonte: Documentos levantados pela autora

Sintetizando a trajetória desses cinco órgãos, em termos de sua participação formal na trajetória da $\mathrm{EaD}$, constata - se no Quadro 1 que:

1. Em relação ao INEP, somente no período 2008 a 2010 é registrada uma manifestação de parceria formal entre este órgão e o SEED no sentido de criar instrumentos específicos para a avaliação de cursos a distância. A partir de 2011, após a extinção do SEED, somente as informações estatísticas em relação à EaD presentes, dados para avaliação ficaram dispersos nos instrumentos de avaliação regulatória conjunta de cursos de graduação presenciais e a distância.

2. CAPES manteve sua atuação na pós-graduação stricto sensu. Entretanto, ao receber a incumbência de operacionalizar a $\mathrm{UaB}$, criou uma Diretoria de Educação a Distância que permanece até hoje. No final de 2017, a Fundação recebeu mais um acréscimo de atribuições relacionadas à $\mathrm{EaD}$ com a abertura à criação de mestrados e doutorados na modalidade a distância, em vias de regulamentação. 
3. Em relação aos órgãos de administração direta - SESu, Seed e Seres - constatou-se o empenho do MEC em criar uma secretaria especialmente voltada para a $\mathrm{EaD}$ na década de 1990, antes mesmo da LDB/96. Inicialmente voltada para as questões da metodologia e uso da TICs, relacionadas a programas governamentais utilizando a TICs, gradativamente tornou-se parceira da SESu nos processos de regulação e avaliação de IES e cursos. De parceira passou a ser um órgão mais decisório. Todo este espaço foi absorvido pela SERES, que assumiu o processo como um todo e manteve somente uma coordenação de EaD em seu organograma.

\section{OS ORGÃOS COLEGIADOS DO MEC E A VISIBILIDADE DE OUTROS ATORES INSTITUCIONAIS}

Complementando este mapeamento de atores do MEC, foram destacados dois órgãos colegiados que mantêm interface com a EaD: o Conselho Nacional de Educação (CNE), diretamente vinculado ao Ministro da Educação e a Comissão Nacional de Avaliação da Educação Superior (CONAES), criada para coordenar o sistema SINAES.

O atual Conselho Nacional de Educação (MEC/CNE, 2018), órgão colegiado diretamente vinculado ao Ministro da Educação, foi instituído em 1995 com a finalidade de colaborar na formulação da Política Nacional de Educação e exercer atribuições normativas, deliberativas e de assessoramento ao Ministro da Educação. A idéia de um Conselho Superior foi objetivada em 1911 com a criação do Conselho Superior de Ensino. Várias alterações de título acompanham a trajetória deste Conselho: Conselho Nacional de Ensino, em1925, Conselho Nacional de Educação em 1931, Conselho Federal de Educação em 1961 e, novamente, Conselho Nacional de Educação em 1995.

As Câmaras de Educação Básica e de Educação Superior, que compõem o atual CNE, são constituídas cada uma, por doze conselheiros. A Câmara de Educação Superior (CES) apresentou algumas alterações em suas atribuições nos últimos 12 anos. Passou a se manifestar principalmente nos processos sobre o credenciamento e o recredenciamento de Universidades e Centros Universitários, ficando a cargo do próprio MEC a condução dos processos sobre os cursos de graduação (exceto Medicina, psicologia e Odontologia) e o credenciamento e o recredenciamento das instituições de ensino superior correspondentes.

A CONAES foi criada para coordenar e supervisionar os procedimentos de avaliação do Sistema Nacional de Avaliação da Educação Superior (SINAES), instituído na Lei no 10.861, de 14 de abril de 2004 (BRASIL, 2004). Ela é constituída por 13 representantes sendo: cinco dentro de três órgãos do MEC 
(INEP, CAPES, SERES), três da comunidade acadêmica (estudantes, docentes e corpo técnico-administrativo) e cinco membros de notório saber e competência em avaliação ou gestão da educação superior, indicados pelo Ministro da Educação.

Ao analisar entidades colegiadas como o CNE e a CONAE ficou clara a participação formal de outros atores institucionais na trajetória da regulação/ avaliação da educação superior presencial e a distância. Em recente comunicado à ANPED, com vistas à indicação de candidatos para renovar a composição da Câmara de Educação Superior do CNE, foi divulgada uma relação de 45 entidades civis que possuem este direito, representando diferentes posições sobre o processo de regulação/avaliação vigente. Destacam-se, entre outras, associações científicas como a ANPAE e a ANPED na área da Educação e a ABED, mais diretamente voltada para a Educação a Distância. As três entidades mantêm publicação permanente de periódicos e realizam encontros anuais, regionais e internacionais. A ABED, inclusive, vem publicando desde 2004 um anuário de dados estatísticos da educação a distância.

Por outro lado é importante registrar a atuação de um crescente número de entidades representantes de mantenedoras de IES do setor privado, como o SEMESP por exemplo, que têm como objetivo preservar, proteger e defender o segmento privado do ensino superior brasileiro. Destaca-se, neste grupo, a inclusão da Associação Nacional das Universidades Particulares (ANUP), como uma das novas entidades a ter direito de voto para o CNE. Consultando seu portal (ANUP, 2018) constata-se a presença, entre suas parceiras, da Associação Brasileira para o Desenvolvimento da Educação Superior (ABRAES), representante de alguns dos maiores grupos educacionais privados do país (Anima, Devry, Estácio, Laureate e Kroton), todos com grande interesse na expansão e flexibilização dos cursos modalidade a distância.

\section{O LABIRINTO DOS ATOS DE REGULAÇÃO DA EAD E O PREDOMÍNIO DA AVALIAÇÃO REGULATÓRIA}

A maioria dos estudos sobre atos oficiais que ultrapasse o nível de lei/ decreto encontra uma grande barreira pela frente que é a multiplicidade de portarias normativas, portarias, pareceres, resoluções e notas técnicas que, se por um lado explicam determinados antecedentes ou consequências destes atos oficias, por outro lado dificultam um relato coerente da análise documental. Tornou-se, então necessário delinear uma síntese de atos oficiais que mais afetaram a $\mathrm{EaD}$ e seus atores após a LDB/96. 
Em estudo anterior sobre os atos oficiais ligados à EaD no período 1996 - 2010, Segenreich e Castro (2012) já destacavam a expansão desordenada da $\mathrm{EaD}$ no período anterior à Regulamentação da EaD em 2005, com a explosão de matrículas de cursos a distância e de criação de polos na rede privada, muitas vezes em instituições não universitárias, sem o devido controle e avaliação do MEC. Em 2004 abre-se mais uma porta à expansão da EaD com a possibilidade de oferecimento de disciplinas semipresenciais nos cursos presenciais.

Logo em seguida ao Decreto 5.733/2006, na busca de sustar a multiplicação incontrolada de polos de apoio presencial, é emitida a Portaria 02 de 10 de janeiro de 2007 (BRASIL, 2007b), estabelecendo a avaliação in loco de todos os pólos. Em 2009, a Portaria no 10/2009 (BRASIL/MEC, 2009b) volta atrás dessa proposta estabelecendo a avaliação in loco por amostragem, como reconhecimento da inviabilidade da proposta inicial. Culminando este período de aumento do controle da educação a distância um decreto assinado em dezembro de 2007, aumenta ainda mais o nível de exigência para credenciamento de instituições e polos assim como de cursos ministrados nos polos. Segenreich e Castro (2012, p.114), concluem em seu estudo que, entre 2007 e 2010 “o Estado assume, assim, o papel de estabelecer políticas de acompanhamento e avaliação do processo de expansão do sistema educacional, sujeitas a standers de acreditação de qualidade", como indicam os instrumentos do INEP aprovados em 2011.

Obedecendo à proposta de estabelecer como foco o biênio 2016/2017, foram selecionados os seguintes atos oficiais que retratam a variedade de fontes do levantamento: Resolução CNE/CES no 1 de 11 de março de 2016; Portaria 1.134 de 10 de outubro de 2016; Decreto no 9.057 de 25 de maio de 2017; a Portaria 11 de 20 de junho de 2017; e, o Parecer CNE/CES n 462/2017.

Estes documentos se referem ao biênio 2016 - 2017 mas isto não significa que o período 2008 - 2015 não tenha sido palco de embates sobre a educação a distância na educação superior. O Plano Nacional de Educação foi aprovado em 2014, depois de longo percurso pelo CNE e é importante registrar que, em sua meta 12/estratégia 12. 20, a proposta de ampliação dos benefícios do FIES e do ProUni aos estudantes de cursos superiores a distância foi objeto de muita discussão por parte de atores institucionais da rede privada.

Neste mesmo período o CNE iniciou a discussão sobre novas diretrizes e normas nacionais para a oferta de programas e cursos de Educação Superior a Distância que geraram um parecer do CES, aprovado no segundo semestre de 2015. No ano seguinte sua proposta de resolução foi aprovada no ano seguinte: a Resolução CNE/CES no 1 de 11 de março de 2016 (BRASIL/MEC/CNE, 2016). Nela é reafirmada a concepção da educação a distância como modalidade não aceitando a idéia de ela possa ser uma metodologia e, com isso, mantendo como 
um todo as normas e processos de autorização e credenciamento de instituições e cursos a distância. No que se refere à avaliação, o artigo 20 da resolução estabelece que caberá ao INEP, em articulação com a Seres, a SESu, a CONAES, a CAPES e o CNE, no prazo de 120 dias: I - a organização de padrões e parâmetros de qualidade da EaD, na perspectiva institucional; II - a definição de instrumento de avaliação externa para fins de credenciamento e recredenciamento institucional, autorização e reconhecimento de cursos superiores na modalidade a distância; III - o estabelecimento de processo avaliativo dos(as) estudantes em formação e concluintes em cursos superiores na modalidade a distância.

Esta Resolução sofreu muitas críticas do setor privado na medida em que não consideraram aceitas as reivindicações feitas durante os debates públicos no CNE. Em artigo de capa da revista do Semesp, publicado por uma consultora de recursos humanos (HETSCHKO, 2016, s/p), são reportadas as críticas de vários representantes de IES privadas sobre a Resolução. Destacamos aqui seu registro sobre as principais proposições consideradas pela ABED como não atendidas, em carta endereçada ao Ministro da Educação:

1. Autorização e regulamentação do uso de bibliotecas digitais.

2. Autorização e regulamentação para expansão de polos das IES que tenham IGC contínuo igual ou superior a 4, sendo que a IES pode expandir o número de pólos a cada dois anos, sem necessitar de visita prévia para sua ativação.

3. Permissão para que sejam constituídas IES para oferta exclusiva da modalidade a distância.

4. Definição da modalidade dos cursos considerando o maior percentual da modalidade de oferta das atividades de ensino e aprendizagem.

5. Permissão para que as IES sejam efetivamente autônomas [...]

6. Revisão dos referenciais de qualidade [...] assim como a necessidade da revisão da Portaria no 40 de 2007 [...].

Em outubro de 2016, a Portaria no 1.134 (BRASIL/MEC, 2016) revoga uma portaria de 2004, que permitia a inserção de disciplinas semipresenciais em cursos presenciais, com 12 anos de vigência sem ser atingida pelos que vários atos oficiais de endurecimento da regulação para a educação a distância. A medida provocou novos protestos do setor privado. A utilização da expressão "disciplina semipresencial" na portaria de 2004 e não "modalidade a distância" permitiu que as IEs inserissem estas disciplinas no currículo dos cursos presenciais, sem que fosse dada nenhuma orientação sobre a forma como as IES deveriam implementar o ensino misto ou híbrido, como mostrou o estudo de Silva, Maciel e Alonso (2017) sobre a hibridização do ensino nos cursos de graduação presenciais das universidades federais.A Portaria 1.134/2016 também não fornece nenhuma orientação adicional a respeito, somente passa a exigir sua presença nos 
projetos pedagógicos incluindo métodos e práticas de ensino-aprendizagem que incorporem o uso integrado de tecnologias de informação e comunicação para a realização dos objetivos pedagógicos, bem como prever encontros presenciais e atividades de tutoria, com profissionais qualificados para esta função.

Em maio de 2017, é assinado o Decreto no 9.057 (BRASIL, 2017) que regulamenta o art. 80 da LDB/96 e quase um mês depois é editada a Portaria $\mathrm{n}^{\circ} 11$ de 20 de junho de 2017 (BRASIL/MEC, 2017) que estabelece normas para o credenciamento de instituições e a oferta de cursos superiores a distância, em conformidade com o referido decreto. Ricardo (2017) faz uma análise desta nova legislação e enumera entre as novidades: permissão que as IES credenciem para oferta de cursos de EaD, na graduação e na pós-graduação lato sensu sem a necessidade de credenciamento para a modalidade presencial; os procedimentos de avaliação in loco ocorrerão apenas nas sedes das IES, sem a necessidade de verificação dos pólos; a IES já criadas para EaD terão autonomia de criar novos pólos com base no conceito institucional da IES. O autor conclui que

o nível de exigência para o funcionamento da $\mathrm{EaD}$, por meio de decretos, representou uma disputa político-ideológica entre a Associação Brasileira de Mantenedoras do Ensino Superior (ABMES) e o MEC por aquela possuir a hegemonia das matrículas e cursos ofertados. (RICARDO, 2017, p. 24)

Finalmente, nova abertura para a expansão da EaD será o Parecer CNE/CES no 462/2017 (BRASIL/MEC/CNE, 2017), já aprovado, que trata da normas referentes à pós-graduação stricto sensu no país. A proposta de Resolução a ele anexada permite que as instituições credenciadas para a oferta de cursos a distância possam propor programas de mestrado e doutorado nesta modalidade e que caberá à Capes a definição dos procedimentos avaliativos referentes aos cursos de mestrado e doutorado na modalidade a distância. No texto do parecer está liberada a possibilidade de propor estes programas a partir de sua homologação (setembro de 2017).

Nos últimos dias de 2017 um novo decreto ainda é assinado. O Decreto nº 9.235, de 15 de dezembro de 2017 (BRASIL, 2017) dispõe sobre o exercício das funções de regulação, supervisão e avaliação das instituições de educação superior e dos cursos superiores de graduação e de pós-graduação no sistema federal de ensino, tanto na modalidade presencial como a distância. Cinco decretos são revogados, destacando-se os Decretos no 5.773/2006 e n ${ }^{\circ} 6.303 / 2007$, integrantes deste texto. Uma análise do impacto desse decreto na educação superior a distância vai se fazer sentir no decorrer do ano de 2018 se não forem emitidos mais atos oficiais que reforcem ou se contraponham às medidas nele indicadas.. 
No que se refere à avaliação da educação superior, o divisor de águas da legislação referente à avaliação institucional e de cursos superiores no Brasil deveria ser criação do SINAES pela Lei no 10.861, de 14 de abril de 2004 (BRASIL, 2004), já referida quando da análise da trajetória do INEP. É importante destacar sua finalidade expressa no primeiro artigo da Lei.

O SINAES tem por finalidade a melhoria da qualidade da educação superior, a orientação da expansão da sua oferta, o aumento permanente da sua eficácia institucional e efetividade acadêmica e social, e especialmente a promoção do aprofundamento dos compromissos e responsabilidades sociais das instituições de educação superior, por meio da valorização de sua missão pública, da promoção dos valores democráticos, do respeito à diferença e à diversidade, da afirmação da autonomia e da identidade institucional.

Esta proposta de avaliação tem sido defendida desde a década de 1980, quando foi desenvolvido o Programa de Avaliação da Reforma Universitária (PARU) e, na década de 1990, o Programa de Avaliação Institucional das Universidades Brasileiras (PAIUB). No relatório em que se propõe o SINAES são registrados os reveses sofridos por estes dois programas tomando como exemplo a proposta de avaliação da Educação Superior vinda do Grupo Executivo para a Reforma da Educação Superior (GERES) em 1985. Utilizando uma concepção regulatória, apresentava a avaliação como contraponto à autonomia das IES, dando relevo às dimensões individuais, seja do alunado, seja dos cursos e instituições, embora se mantenha a preocupação com as dimensões institucionais. Conclui o relatório de proposta do SINAES (MEC, 2003, p.15) que "deste modo, vem ocorrendo uma redução do conceito de avaliação, enfatizada na sua dimensão de supervisão, ou, ainda mais restritamente, de controle a partir de processos organizados e executados pelo próprio Ministério, com a colaboração das comissões".

Segundo Sobrinho (2008), que foi o presidente da comissão que elaborou a proposta do SINAES, a Lei $\mathrm{n}^{\circ} 10.861 / 2004$ determina que a avaliação da educação superior brasileira deve cumprir-se como sistema. Ele dá destaque aos seguintes pontos: avaliação institucional interna e externa, contemplando a análise global e integrada das dimensões, estruturas, relações, compromisso social, atividades, finalidades e responsabilidades sociais das instituições de educação superior e de seus cursos; caráter público; respeito à identidade e à diversidade de instituições e cursos; participação do corpo discente, docente e técnicoadministrativo e da sociedade civil.

Teoricamente as perspectivas eram de inaugurar um novo ciclo de avaliação no sistema de educação superior. Entretanto, a implantação do SINAES é atropelada por medidas que resultam da atribuição, ao INEP, de sua operacionalização. Segundo Sobrinho (2008, p. 821) 
A avaliação da educação superior brasileira, em razão das recentes medidas do INEP, está deixando de ser uma produção de significados, questionamento sobre a pertinência e a relevância científica e social da formação e dos conhecimentos, e passando a reduzir-se à medida e ao controle.

Nesta mesma linha de pensamento Sguissardi (2008, pp.857/858) critica a deturpação dos objetivos do SINAES em 2008, nos seguintes termos:

A criação recente, pelo MEC, do Conceito Preliminar de Cursos - CPC e do Índice Geral de Cursos das Instituições de Educação Superior - IGC é apenas um exemplo de certo modelo de regulação que contradiria frontalmente um dos objetivos básicos do Sistema Nacional de Avaliação da Educação Superior - SINAES, isto é, a gradativa implementação da cultura de avaliação nas IES.

$\mathrm{Na}$ análise da trajetória do INEP e, posteriormente, de sua convergência com os instrumentos da CAPES nos permite constatar que permanece ainda a avaliação com uma perspectiva predominantemente regulatória no sistema, incluindo a EaD. Isto não impede que muitas instituições tenham adotado princípios defendidos pelo SINAES, estabelecendo o que Sguissardi conceitua como cultura da avaliação. Estas IES seriam um excelente objeto de estudo: a análise de experiências bem sucedidas no lugar de apontar somente críticas.

\section{CONSIDERAÇÕES FINAIS}

Em primeiro lugar, é importante comentar alguns problemas enfrentados no processo de investigação. Quando se tenta recuar um pouco mais no tempo, as informações sobre as instituições e seus atores tende a escassear e finalmente desaparecer dos portais oficiais, principalmente se estiverem extintas como no caso da SEED ou dos instrumentos de avaliação voltados para a EaD, sem acesso no portal do INEP. Os instrumentos construídos pelo INEP junto com a SEED não constam na relação de instrumentos do INEP como um documento completo mas estão na relação instrumentos a serem analisados quando da reformulação dos instrumentos de avaliação pela SERES em 2010/2011; eles são os únicos sem acesso direto.

No mapeamento dos atos oficiais constatou-se que seu cabeçalho de embasamento jurídico inicial e artigos finais de revogação parcial ou total de documentos anteriores constituem um labirinto para o pesquisador e, certamente, para os gestores das instituições de educação superior, dando margem a interpretações controvertidas. No caso da Resolução CNE/CES n ${ }^{\circ}$ 1/2016, o 
problema foi sua ausência nos atos oficiais posteriores à sua aprovação, ela foi atropelada pelo Decreto 9.057/2017 mas não foi revogada. É um desses caminhos que merecem investigação.

Em relação à avaliação fica clara a predominância da avaliação regulatória, mesmo com as atualizações feitas tanto pelo INEP como pela CAPES. Um caminho de investigação seria localizar e analisar experiências de IES credenciadas para a educação a distância conseguiram implantar parcial ou completamente os princípios do SINAES tanto na rede pública como na rede privada. A socialização de experiências exitosas, relatadas em estudos de caso, pode estimular outras instituições a seguir este caminho. Finalmente, a opção de tomar como um dos eixos da pesquisa documental um mapeamento dos principais atores institucionais envolvidos nos atos oficiais e nos instrumentos avaliação regulatória abre, também, vários caminhos de investigação no que diz respeito às relações de poder entre instituições e atores individuais.

\section{REFERÊNCIAS}

ANUP. Associadas. ABRAES. Disponível em: http://www.anup.com.br / portal/pagina/index/id/30/secao/2. Acesso em: 1 fev. 2018.

BRASIL. Lei $\mathrm{n}^{\circ}$ 10.861, de 14 de abril de 2004. Institui o Sistema Nacional de Avaliação da Educação Superior - SINAES e dá outras Providências. 2004. Disponível em: www.planalto.gov.br/ccivil_03/_ato2004-2006/2004/lei/110.861. htm. Acesso em: 18 dez. 2017.

Decreto $\mathrm{n}^{0}$ 5.622, de 19 de dezembro de 2005. Regulamenta o art. 80 da Lei $n^{\circ}$ 9.394, de 20 de dezembro de 1996, que estabelece as diretrizes e bases da educação nacional. 2005. Disponível em: <http://www.planalto.gov.br / ccivil_03_Ato20042006/2005/Decreto/D5622.htm>. Acesso em: 18 dez. 2017.

Decreto $\mathrm{n}^{\circ} \mathbf{5 . 7 7 3}$, de 09 de maio de 2006. Dispõe sobre o exercício das funções de regulação, supervisão e avaliação das instituições de educação superior e cursos superiores de graduação e seqüenciais no sistema federal de ensino. 2006. Disponível em: http://www.planalto.gov.br/ccivil_03/_ato2004-2006/2006/ Decreto/D5773.htm. Acesso em: 18 dez. 2017.

Decreto $\mathrm{n}^{\mathrm{o}}$ 6. 303, de 12 de dezembro de 2007. Altera dispositivos dos Decretos nos 5.622, de 19 de dezembro de 2005, que estabelece as diretrizes e bases da educação nacional, e 5.773, de 9 de maio de 2006, que dispõe sobre 
o exercício das funções de regulação, supervisão e avaliação de instituições de educação superior e cursos superiores de graduação e seqüenciais no sistema federal de ensino. 2007. Disponível em: http://www.planalto.gov.br/ccivil_03/_ ato2007-2010/2007/decreto/d6303.htm. Acesso em 10 jan. 2018.

Decreto $\mathbf{n}^{\circ} \mathbf{7 . 4 8 0}$, de 16 de maio de 2011. Aprova a Estrutura Regimental e o Quadro Demonstrativo dos Cargos em Comissão do Grupo-Direção e Assessoramento Superiores - DAS e das Funções Gratificadas do Ministério da Educação e dispõe sobre remanejamento de cargos em comissão. 2011. Disponível em: http://www.planalto.gov.br /ccivil_03/_ato2011-2014/2011/ decreto/d7480.htm. Acesso em: 17 dez. 2017.

. Decreto $\mathbf{n}^{\circ} \mathbf{7 . 6 9 0}$, de 02 de março de 2012. Aprova a Estrutura Regimental e o Quadro Demonstrativo dos Cargos em Comissão e das Funções Gratificadas do Ministério da Educação. 2012. Disponível em: http://www.planalto.gov.br/ ccivil_03/_ato2011-2014/2012/decreto/d7690.htm. Acesso em: 17 dez. 2017.

. Decreto $\mathbf{n}^{\mathbf{0}} \mathbf{9 . 0 5 7}$, de 25 de maio de 2017- Regulamenta o art. 80 da Lei n ${ }^{\circ}$ 9.394, de 20 de dezembro de 1996, que estabelece as diretrizes e bases da educação nacional. 2017a. Disponível em: www.planalto.gov.br/ccivil_03/_.../2017 / decreto/D9057.htm. Acesso em: 18 dez. 2017.

. Decreto $\mathrm{n}^{\mathbf{0}} \mathbf{9 . 2 3 5}$, de 15 de dezembro de 2017. Dispõe sobre o exercício das funções de regulação, supervisão e avaliação das instituições de educação superior e dos cursos superiores de graduação e de pós-graduação no sistema federal de ensino. 2017b Disponível em: www.planalto.gov.br/ ccivil_03/_...2017/Decreto/D9235.htm. Acesso em: 18 dez. 2017.

. MEC/CNE. Resolução CNE/CES n ${ }^{\circ}$ 1, de 11 de março de 2016 Estabelece Diretrizes e Normas Nacionais para a Oferta de Programas e Cursos de Educação Superior na Modalidade a Distância. Disponível em: http://portal. mec.gov.br/escola-de-gestores-da-educacao-basica/323-secretarias-112877938/ orgaos-vinculados-82187207/34891-resolucoes-cne-ces-2016. Acesso em: 10 jan. 2018. 
MEC. Portaria $\mathrm{n}^{\mathbf{0}}$ 2.051, de 9 de julho de 2004 que regulamenta os procedimentos de avaliação do Sistema Nacional de Avaliação da Educação Superior (SINAES), instituído na Lei no 10.861, de 14 de abril de 2004. Disponível em: portal.mec.gov.br/arquivos/pdf/PORTARIA_2051.pd. Acesso em: 24 jan. 2018.

MEC. Portaria Normativa $\mathbf{n}^{\mathbf{0}} \mathbf{1}$, de 10 de janeiro de 2007. Calendário do ciclo avaliativo do SINAES, triênio 2007/2009. 2007a. Disponível em: portal. mec.gov.br/seed/arquivos/pdf/legislacao/portaria1.pdf. Acesso em: 24 jan. 2018.

MEC. Portaria normativa $\mathbf{n}^{\mathbf{0}}$ 2, de 10 de janeiro de 2007. $2007 \mathrm{~b}$.

Dispõe sobre os procedimentos de regulação e avaliação da educação superior na modalidade a distância. 2017b. Disponível em: http://portal.mec.gov.br/seed/ arquivos/pdf/legislacao / portaria2.pdf. Acesso em: 24 jan. 2018.

. MEC. Portaria $\mathbf{n}^{\circ}$ 318, de 2 de abril de 2009. Transfere à Coordenação de Aperfeiçoamento de Pessoal de Nível Superior-Capes - a operacionalização do Sistema Universidade Aberta do Brasil - UAB. Brasilia: MEC/Capes, 2009. Disponível em: < http://uab.capes.gov.br/images/stories/downloads/legislacao/ Portaria3182Abr09_UAB paraCAPES.pdf>. Acesso em: $10 \mathrm{dez} 2017$.

. MEC. Portaria $\mathbf{n}^{\mathbf{0}}$ 10, de 02 de julho de 2009. Fixa critérios para dispensa de avaliação in loco e dá outras providências. Disponível em: http:// www.semesp.org.br/portal/pdfs/juridico2009_OLD/Portarias/02.07.09/ Portaria\%2010-2009.pdf. Acesso em: 10 dez 2017.

. MEC. Portaria no 1.134, de 10 de outubro de 2016 - Revoga a Portaria MEC no 4.059, de 10 de dezembro de 2004, e estabelece nova redação para o tema. Disponível em: https://abmes.org.br/legislacoes/detalhe/1988/portaria-n-1134. Acesso em: 10 jan. 2017.

. MEC/CNE. Parecer CNE/CES n ${ }^{\circ}$ 462, de 14 de setembro de 2017. Normas referentes à pós-graduação stricto sensu no país. 2017a. Disponível em: http://portal.mec.gov.br/docman/outubro-2017-pdf/73971-pces462-17-pdf/ file. Acesso em: 17 jan. 2018. 
. MEC. Portaria no 11, de 20 de junho de 2017 - Estabelece normas para o credenciamento de instituições e a oferta de cursos superiores a distância, em conformidade com o Decreto no 9.057, de 25 de maio de 2017. Disponível em: abmes.org.br/legislacoes/detalhe/2178/portaria-normativa-n-11. Acesso em: 10 jan. 2017.

HETSCHKO, K. Muito debate poucos avanços. Capa. Revista do Ensino Superior. Semesp. 25 de abril de 2016. Edição 208. Disponível em: http://www. semesp.org.br /noticias/muito-debate-poucos-avanços. Acesso em: 21 jan. 2018.

MANCEBO, D; OliveirA, J.F. de; SILVA JÚNIOR, J. dos R. Políticas, gestão e direito à educação superior: novos modos de regulação e tendências em construção. (projeto de Pesquisa versão 3).maio de 2017, p. 10.

MEC. Sistema Nacional de Avaliação da Educação Superior SINAES: Bases para uma nova proposta de avaliação da Educação Superior. 2003. Disponível em: http://portal.mec.gov.br/arquivos/pdf/sinaes.pdf. Acesso em: 12 fev. 2018.

. Coordenação de Aperfeiçoamento de Pessoal de Nível Superior. (CAPES). História e missão. Disponível em: http://www.capes.gov.br/historia-e-missao. 2018 Acesso em: 17 dez. 2018.

- Instituto Nacional de Estudos e Pesquisas Educacionais Anísio Teixeira (INEP) . Sinopse Estatística da Educação Superior de 2016. Brasilia: INEP. 2017. Disponível em: http://portal.inep.gov.br/superior-censosuperior-sinopse Acesso em: 10 dez. 2017.

. Secretaria de Educação a Distância (SEED). Referenciais de qualidade para a educação superior a distância. Brasilia, DF. agosto de 2007. Disponível em: portal.mec.gov.br/seed/ arquivos/pdf/referenciaisead.pdf Acesso em: 10 jan. 2018.

Secretaria de Educação Superior (SESu). Apresentação. 2018. Disponível em: http:/ / portal.mec.gov.br / sesu-secretaria-de-educacao-superior/ apresentação. Acesso em: 10 jan. 2018. 
. Secretaria de Regulação e Supervisão da Educação Superior (Seres). Quem é quem. 2018 Disponível em: http://portal.mec.gov.br/secretaria-de-regulacaoe-supervisao-da-educacao-superior-seres/quem-e-quem. Acesso em: 10 jan. 2018.

Conselho Nacional de Educação (CNE). Histórico. 2018. Disponível em: http:/ / portal.mec.gov.br/index.php?option $=$ com_content\&view $=$ article\&id $=1$ 4306: cne-historico\&catid=323:orgaos vinculados. Acesso em: 11 jan. 2018.

INSTITUTO NACIONAL DE ESTUDOS E PESQUISAS EDUCACIONAIS ANÍSIO TEIXEIRA (INEP). História. 2018. Disponível em: http://portal. inep.gov.br/historia. Acesso em: 11 jan.2018.

QUIVY, R.; CAMPENHOUDT, L. Manual de Investigação em Ciências Sociais, Lisboa, Gradiva, 2005.

RICARDO, J. S. Impacto da nova regulamentação da $\mathrm{EaD}$ para as instituições de educação superior. EaD UFBA em Revista, Salvador, Número 22017 Disponível em: http://www.eademrevista.ufba.br/wpcontent/themes/revista/ docs/EaD_UFBA\%20em\%20Revista-N2_SEAD.pdf. Acesso em: 19 jan. 2018.

SEGENREICH, S. C. D.; CASTANHEIRA, M. O espaço da educação superior a distância na expansão da educação superior brasileira pós-LDBEN/1996. In: SOUSA, José Vieira de (org.). Expansão e avaliação da educação superior brasileira: formatos, desafios e novas configurações. Belo Horizonte, MG: Fino Traço/ Fa0culdade de Educação da Universidade de Brasília, 2015, p. 115 -134 .

SEGENREICH, S. C. D.; CASTRO, A. M. D. A . A inserção da educação a distância no ensino superior do Brasil: diretrizes e marcos regulatórios, Revista Educação em Questão, Natal, v. 42, n. 28, p. 89-118, jan./abr. 2012.

SGUISSARDI, V. Regulação estatal versus cultura de avaliação institucional? Avaliação, Campinas; Sorocaba, SP, v. 13, n. 3, p. 857-862, nov. 2008.

SILVA, M. R. C. da, MACIEL C., ALONSO, K.M. Hibridização do ensino nos cursos de graduação presenciais das universidades federais: uma análise da regulamentação. RBPAE, v. 33, n. 1, p. 095 - 117, jan./abr. 2017. 
SOBRINHO, J. D. Qualidade, avaliação: do SINAES a índices. Avaliação, Campinas; Sorocaba, SP, v. 13, n. 3, p. 817-825, nov. 2008.

STELLA CECILIA DUARTE SEGENREICH é Licenciada em Pedagogia e mestre em Educação pela Pontifícia Universidade Católica do Rio de Janeiro (PUC/ RJ). Master of Arts pela Universidade de Stanford. Doutora em Educação Brasileira pela Universidade Federal do Rio de Janeiro (UFRJ). Experiência docente como professora associada da PUC/RJ, adjunta da UFRJ e titular da Universidade Católica de Petrópolis (UCP). Tem desenvolvido nos últimos vinte anos estudos sobre a educação superior a distância com ênfase nas questões relacionadas às políticas públicas, arquiteturas acadêmicas, sistema de tutoria e avaliação. Atualmente pesquisa também as questões da privatização e da internacionalização da educação a distância. Autora de diversos artigos e capítulos de livro, organizou três coletâneas sobre educação superior. Como professora aposentada da UFRJ, participa da rede de pesquisadores ligada ao GT 11 da ANPED (Política da educação superior), integrando o eixo dois do programa de pesquisa do Universitas/BR. E-mail: stella.segen@gmail.com

Recebido em fevereiro de 2018 Aprovado em abril de 2018 